\title{
College Non-computer Professional C Language Course Teaching Problems in Solution
}

\author{
Ruirui Chen ${ }^{1}$ \\ ${ }^{1}$ Zhengzhou University of Industrial Technology, the School of Information Engineering, Henan, \\ China, 451100 \\ ${ }^{a}$ email
}

Keywords: C Language, Course Teaching, College Students

\begin{abstract}
College students contact with $C$ language learning that just opened, the thinking habit of learning $C$ language is still in its not fit for the state. Learning $C$ language, there has been no contact device on the physical plane, don't know where is the $C$ language with its cannot insist on learning. The study is through the clear learning objectives, dispersing the difficulty and reduces the difficulty of learning $\mathrm{C}$ language, to the true temperature measurement engineering guide students' learning interest; make smoothly for $\mathrm{C}$ language learning.
\end{abstract}

\section{Introduction}

Because the $\mathrm{C}$ language is concise and compact, has structured control statements, generate the target code is of high quality, good portability and flexibility, are choose $\mathrm{C}$ language as the first computer language teaching. $\mathrm{C}$ language in addition to the above has the advantages of high level language also allows direct access to physical addresses, and more adapted to the underlying application software development, is an embedded electronic product development, chip design, etc; The Linux kernel is mainly written in $\mathrm{C}$ language. Based on the above characteristics, even if the object-oriented program design popular today, many companies still use $\mathrm{C}$ language as programming language of choice for the development to solve the field of application. , however, not satisfactory, the teaching of $\mathrm{C}$ language and $\mathrm{C}$ language was the first computer language students entering the university, plus the abstractness of the $\mathrm{C}$ language itself, language express logical relationship is complicated, combined with the past in the $\mathrm{C}$ language teaching can't bind to solve practical problems and difficulty, causes the student to study $\mathrm{C}$ language process purpose is not clear, can't gain a sense of achievement from learning $C$ language, reduces the interest in learning, learning to finally able to insist on down to a very low proportion of students. Often leads to start to learn $\mathrm{C}$ language ambitions, intermediate stage are confused, the last stage. The serious influence of $\mathrm{C}$ language teaching quality and teaching effect.

\section{Language Course Teaching Concrete Train of Thought}

$\mathrm{C}$ language is a general-purpose computer programming language, is used widely. C language design goal is to provide a simple and easy way to compile, dealing with low-level storage, produce a small amount of machine code and does not require any operating environment support can run programming language. Although $\mathrm{C}$ language provides many low-level processing capabilities, but still maintained cross-platform features, as a standard specifications write $\mathrm{C}$ language program can be compiled on many computer platform, even include some of the embedded processor (MCU or MCU) and super computer operation platform. In the $1980 \mathrm{~s}$, in order to avoid the differences between developers use $\mathrm{C}$ language syntax, by national bureau of standards for the $\mathrm{C}$ language to set a set of complete international standard grammar, known as the ANSI C, as the initial standard C 
language. Mainly from the characteristics of $C$ language and problems arising from the students in the past, through enhancing knowledge, dispersed the difficulty, to the actual temperature measurement engineering problems as the $\mathrm{C}$ language learning carrying medium, by inspiring students' learning interest, strict with students, fully trust students, encourage students to keep learning, give play to the role of teacher love in the process of teaching, make students complete $\mathrm{C}$ language teaching, students in the learning process ultimately to achieve clear, learning interest and the purpose of their major, help students familiar with the use of $\mathrm{C}$ language in engineering. Improve the students' comprehensive vocational ability and quality, for the smooth employment to lay a good foundation.

\section{Concrete Steps and Contents of the Research Content}

Summing Up the Knowledge of the $\mathbf{C}$ Language. For the $C$ language knowledge comb clear to facilitate students' memory, the C language knowledge into static knowledge and dynamic knowledge.

Static knowledge. (1) Some concepts such as: operator, identifiers, keywords, data types, expression, statement, array, function, pointer, etc., as operators, identifier, data types, such as concepts easy to understand, but another kind of concept (also includes usage) such as references, Pointers and arrays, structures, and the appropriate concept is the concept of the new contact and abstraction, they also involves the use of computer internal working process, the difficulty is bigger, need to repeatedly through example let students understand the definition, on the basis of understanding in trying to application. In this part of the need to focus on strengthening practice teaching.

(2) The format of the C language, can be summarized as "function head and a main function" structure, this is a $\mathrm{C}$ language program must format, give detailed $\mathrm{C}$ language is like to wear a uniform, see the uniforms will know is a $C$ language program; Each of the $C$ language program, in turn, have to wear this uniform. Specific what is content in the C language program, is about to see the contents of the \{\} .

Dynamic knowledge including algorithms, function, the use of the statement, compile tools software.

(1) Algorithm is a very complex is very broad and there is a big difficult problem, but in the algorithm to solve the problem of common engineering problems and life is not very difficult. Clear algorithm is only the methods and steps to solve the problem, not the concept of algorithm of mystery. Will use C language implementation for the common algorithm can, for example: the general numerical calculation, the logic operation, search, sort, look-up table, etc.

(2) Function: explicit function calls, parameter transmission, function is an important concept in $\mathrm{C}$ language and part of the $\mathrm{C}$ programming language is the basic component of unit, many of the functions of computer is done by function. To use power n-th root, sine, cosine, tangent cotangent index operation, differential, integral and related numerical calculation function, can complete the general numerical calculation, by looking at data will use common mathematical functions and the necessary other commonly used library function is ok, to be separately in view of the practice in teaching.

(3) The relationship between the expressions and statements of $\mathrm{C}$ language programming statements: the $\mathrm{C}$ language statement is divided into four categories: to strengthen students' memory order statement, select statements, looping statements, transfer control statements. Statements in the $\mathrm{C}$ programming language in $\mathrm{C}$ language teaching is the core of the most difficult and most challenging part, only to learn this part, only could use the $\mathrm{C}$ language programming. Teaching 
important points of this part should be kept separate. The statement of order structure, the difficulty is small, in combination with the engineering algorithm can smoothly. The difficulty of the select statement has two, one is writing format and usage of several select statement. Second select statement is nested, the logical relationship between a set of a layer, the logic of nested logic habit is not easy, must be conducted step by step from simple to complex, let the students get the C language logic nested way the habit of looking for problem solving. To the cycle of simple sentence structure to make greater efforts to strengthen began practicing with a certain amount of circulating small examples to strengthen student's understanding of loop statements, reach the level of proficiency in, and then loop statement which let the students know cycle in combination with the engineering in the actual application in engineering. Nested loop of the most difficult, must through the instance of teaching in a nested loop repeatedly training, reach the level of proficiency, and let the students find their own life in a nested loop example of nested logic to adapt to the cycle. Finally experience carefully measuring engineering of the use of nested loop. To transfer control statements teaching should emphasize the three kind of control statements application condition and matters needing attention, to prevent improper use is program into the infinite loop. When it is necessary to let students experience through the use of a wrong mistake to use produce results.

(4) C language compiler platform, there are several can be used to compile platform, usually using the Visual $\mathrm{C}++6.0$ have found in teaching, has yet to start, $\mathrm{C}$ language learning was stumped by compiling platform, select "aha lei" [3] written in C language learning platform, such as fitting in Visual C ++6.0 to compile software.

To Establish A Real Temperature Measuring Project. Hardware design engineering. Using C language development of single chip microcomputer for thermostat sensor measuring the temperature of the air. Thermostat and the oscillator, 555, temperature changes, the thermostat resistance changes, the oscillation frequency changes, the oscillation frequency can be determined through single chip microcomputer, compared with the standard temperature value can be calculated. A hardware circuit design and software design of a PCB, good welding circuit components. Set aside.

For temperature measurement hardware circuit part temperature measuring software code is as follows:

\# include

\# include

Float the find (float resv)

\{Data float temper; Idata int top, bottom, mid;

If (resv $>=39028$ ) temper $=-30$;

Else if (resv $<=831$ ) temper $=60$;

The else

$\{$ flag $=1 ; / / *$ assume that the input number in the table column

Top = 90; Bottom = 0; Mid = (top + bottom $) / 2$;

While (flag)

Return (temper);

\}

The teaching. In teaching beginning stages:

(1) The students show the hardware system of engineering function, demonstration temperature measurement process, tell the students this system is to use $C$ language to write the application, let the students know that to learn $\mathrm{C}$ language well after can write your own control program. 
(2) The knowledge of C language, tell students contains C language knowledge and learning methods.

(3) Clear C language learning difficulties.

(4) To establish a study group.

Teaching stage. According to the knowledge and ability of the $\mathrm{C}$ language teaching, teaching new knowledge need for students to practice over and over again until it is skilled. Has the difficulty in the teaching, the teaching difficulty is decomposed into several steps, for example, in the interpretation of the loop, the loop statement every cycle of operation results in the form of a written, so write down three to five steps, students will understand the role of the loop statement. And for example to explain in detail a nested loop, start the nested statements in the most simple form, then gradually make nested statements complex, through this to take apart the difficulty, learning difficulty is reduced, when master certain knowledge, learning self-confidence will increase, help students to stick to the back of the study.

Start the temperature measurement program to students, let students find out what they have learned knowledge application in the program at any time, and through the interpretation of the hardware knowledge. Through the actual teaching experiment, at the end of the content of the $\mathrm{C}$ language teaching, students have the hardware for the project, arouse the students' interest in single chip computer knowledge, some students buy their own SCM active self-study books, mobilize the students' learning enthusiasm.

\section{Conclusion:}

Through the $\mathrm{C}$ language to strengthen the knowledge points, difficulty dispersion, to reduce the difficulty of learning, with the engineering practical problems as the medium of $\mathrm{C}$ language knowledge learning, guide students to active learning, the students complete the $\mathrm{C}$ language teaching has a huge role in promoting. Learning students in the process of teaching goal clear, learning interest, improve the effect of the students to learn $\mathrm{C}$ language, can stick to learned significantly increased the number of students in the $\mathrm{C}$ language. But there are some limitations, it is the students are still lack of knowledge of electronics, single-chip computer knowledge, cannot achieve the result of hope. If the $C$ language to open effect will be better after learning single chip microcomputer, students' learning difficulty will be smaller.

\section{References:}

[1] Mao-yam fang, Sun Dingo dings. C language program design [M]. Higher Education Press, 2009 (7).

[2] Yang Fang. Interesting algorithm [M]. Songhai University Press, 2012 (12).

[3] Kleenex. Win2000 security audit for the intruder site [DB/OL]. Focus (safety) in 2004-02

[4] snow. Website building and website development [j]. Silicon Valley. 2008 (23)

[5] Ling Ruiz. Website development stages of education [j]. Theorists. 2005 (08)

[6] Fang Chihuahua. Web design of small education [j]. Journal of Ujungpandang College of education. 2005 (06)

[7] Li Weenie. Basic elements of education website construction [j]. Michelangelo education (consolidated version). 2004 (16)

邮寄地址：郑州市中原区百花路 46 号院 4 号楼三单元，牛丽娜收，电话 13949082769 